REALA, número 15, abril de 2021

Sección: COMUNICACIONES Y COMENTARIOS JURISPRUDENCIALES

Recibido: 01-11-2020

Modificado: 01-03-2021

Aceptado: 08-02-2021

Publicado: $15-04-2021$

DOI: https://doi.org/10.24965/reala.i15.10876

Páginas: $71-85$

\title{
El agujero negro de los premios literarios municipales
}

\section{The black hole of municipal literary awards}

\author{
Miguel José Izu Belloso \\ Tribunal Administrativo de Navarra (España) \\ ORCID: https://orcid.org/0000-0001-9364-9535 \\ mizu@micap.es
}

\section{NOTA BIOGRÁFICA}

Pamplona, 1960. Doctor en Derecho y licenciado en Ciencias Políticas y Sociología. Vocal del Tribunal Administrativo de Navarra. Ha ejercido como abogado y como profesor asociado de Derecho Administrativo en la Universidad de Navarra y en la Universidad Pública de Navarra. Ha sido concejal del Ayuntamiento de Pamplona (1995-1999), presidente de la Mancomunidad de la Comarca de Pamplona (1995-1999) y miembro del Parlamento de Navarra (2003-2007). Secretario de la Asociación Navarra de Escritores/as-Nafar Idazleen Elkartea. Principales publicaciones: La Policía Foral de Navarra (1991); Navarra como problema. Nación y nacionalismo en Navarra (2001); El Tribunal Administrativo de Navarra (2004); Derecho Parlamentario de Navarra (2009); El régimen jurídico de los símbolos de Navarra (VII Premio Martín de Azpilicueta, 2011); El régimen lingüístico de la Comunidad Foral de Navarra (2013); Hemingway en los sanfermines (2019).

\section{RESUMEN}

Se analizan los premios literarios concedidos por las entidades locales, en particular los que conllevan la publicación de las obras premiadas. Pese a que las Administraciones Públicas deben someterse a un procedimiento riguroso que garantice la publicidad y la satisfacción de los intereses públicos en todas sus actuaciones, y más cuando se utilizan fondos públicos, es demasiado frecuente que la concesión de premios literarios se realice ignorando las normas legales aplicables y con ausencia total de transparencia y de garantías para los participantes.

\section{PALABRAS CLAVE}

Derecho premial; subvenciones; entidades locales; procedimiento administrativo; fomento.

\section{ABSTRACT}

This paper analyzes the literary prizes granted by local entities, particularly those that involve the publication of the awarded works. Despite the fact that Public Administrations must undergo a rigorous procedure that guarantees transparency and the satisfaction of public interests in all their actions, especially when public funds are used, it is too usual that the awarding of literary prizes is carried out in violation of the applicable laws and with a total absence of transparency and guarantees for the authors.

\section{KEYWORDS}

Awards; Grants; local entities; Administrative procedure; Promotion.

\section{SUMARIO}

1. INTRODUCCIÓN. 2. UNA NORMATIVA IGNORADA. 3. PUBLICIDAD Y PUBLICACIÓN. 4. IGNOTOS CONCURSANTES. 5. EL JURADO, ESE GRAN DESCONOCIDO. 6. LA ADMINISTRACIÓN PREELECTRÓNICA. 7. UNO DE LOS NUESTROS. 8. AMIGOS PARA SIEMPRE. 9. EL FALLO SERÁ INAPELABLE. 10. EL OSCURO PAPEL DE LAS EDITORIALES. 11. ABANDONAD TODA ESPERANZA. 


\section{INTRODUCCIÓN}

Los premios literarios, en España, uno de los países donde más se conceden, tienen mala prensa. Especialmente, los que conceden las editoriales a novelas inéditas con el fin de publicarlas, que son los más conocidos. Aunque se otorguen mediante convocatoria pública a la que, a menudo, los autores se presentan bajo seudónimo para que la decisión del jurado sea totalmente ecuánime, existe la percepción generalizada de que el premio está concedido de antemano, con frecuencia a un escritor bajo contrato con la propia editorial convocante o a un personaje famoso por motivos ajenos a la literatura a quien se quiere promocionar como escritor. Parece que no constituyen un medio para sacar a la luz obras de especiales méritos literarios ni para descubrir nuevos talentos, sino meras operaciones publicitarias para vender muchos ejemplares de las obras premiadas (Marín Yarza, 2017). Según el escritor, editor y crítico Constantino Bértolo, para quien «algo huele a podrido en nuestro sistema literario» (Bértolo, 2017),

«Es sorprendente que autores y autoras que desde sus tribunas públicas denuncian y se escandalizan de las corrupciones de políticos de tal o cual partido no se sientan aludidos o tocados por esa corrupción que sólo ven en el ojo ajeno. La corrupción que el amaño de los premios representa se vive con tal naturalidad en los medios literarios que referirse a ellos es ganarse inmediatamente la vil condición de envidioso, resentido o frustrado. Quizá de ahí el mafioso silencio que acompaña a tan general práctica».

No pretendo asegurar que todos los premios literarios estén amañados, ni mucho menos. Los hay otorgados con total limpieza y un jurado que aplica puros criterios técnicos. Quiero creer que son los más. Pero me consta que son demasiado abundantes aquellos que están otorgados de antemano, cuando no directamente encargados por la editorial concedente para ser escritos como novela de premio, en los cuales todo el procedimiento de convocatoria, admisión de originales y votación del jurado es puro paripé.

En muchos casos, la cosa no resulta tan grave porque casi todo el mundo sabe lo que hay. En el entorno de la industria editorial, tanto escritores como críticos, periodistas, agentes, editores, saben qué premios no tienen apenas nada de literarios sino mucho de comerciales y están ya adjudicados antes de su convocatoria. En privado, muy poco en público por no enemistarse con quien los concede, se hacen chascarrillos sobre a quién toca obtenerlo en cada edición. Buena parte de los escritores que envían su manuscrito a los premios literarios también saben que, en la mayoría de los casos, no tienen la menor opción de conseguirlos pero, sin renunciar a que suene la flauta en alguna de las muchas convocatorias a las que concurren, se conforman con aspirar a ser finalistas, figurantes en la ceremonia de concesión, con la esperanza de que ello favorezca la publicación de su obra o de que alguien la lea en una editorial importante, lo que ya suele resultar una proeza.

En todo caso, las editoriales poco escrupulosas juegan con su propio dinero y apenas engañan a nadie. La cosa es distinta con los premios literarios a los que me quiero referir, los convocados, financiados y otorgados por ayuntamientos y diputaciones, una práctica en constante crecimiento. No nos vamos a referir a los galardones honoríficos, donde solo se entrega un diploma o una medalla y muy habituales desde tiempo atrás ${ }^{1}$, sino a los premios con dotación económica, normalmente de varios miles de euros, además de la publicación de la obra, que se han multiplicado como hongos en las últimas dos o tres décadas. Y la cosa es distinta porque las entidades locales no juegan con su propio dinero, sino con el de los contribuyentes. Como poderes públicos están obligadas a unas rigurosas pautas de actuación que no son las mismas exigibles a las editoriales privadas. Los ciudadanos, incluidos los escritores que se presentan a un premio literario, tienen derecho a que la gestión de quienes han sido elegidos para ocuparse de los intereses públicos sea ejemplar, impoluta y transparente y, por supuesto, escrupulosamente sometida a la ley. Por desgracia, demasiado a menudo la actuación de las entidades locales en la concesión de premios literarios se halla lejos de cumplir con principios tan elementales. El escritor que, desconfiando de las editoriales privadas, acuda a presentar su obra en un premio convocado por una Administración Pública otorgándole mayores dosis de confianza puede quedar defraudado.

Se ha señalado por la doctrina jurídica que una de las actividades de la Administración que viene mostrándose como más resistente al efectivo sometimiento a derecho es la acción de fomento y, dentro de ella, especialmente los premios culturales, literarios o artísticos. Con excesiva frecuencia se tiende a seguir

1 Por ejemplo, el Premio Cervantes Chico, que otorga el Ayuntamiento de Alcalá de Henares a escritores de lengua castellana cuya trayectoria creadora haya destacado en el campo de la literatura infantil y juvenil. 
viendo su concesión como una actividad graciable, más que discrecional, cuasi inmune a las garantías y controles exigibles a cualquier actuación de los poderes públicos en el Estado de Derecho que define la Constitución española, por no decir que se realiza al margen de la ley (Izu Belloso, 2009).

\section{UNA NORMATIVA IGNORADA}

Y no es que no existan leyes que regulen la concesión de los premios literarios. De un lado, son aplicables las que rigen con carácter general el funcionamiento de las Administraciones Públicas, y, de otro, desde hace unos años tenemos la Ley 38/2003, de 17 de noviembre, General de Subvenciones (LGS), y la legislación autonómica que la complementa o desarrolla. La concesión de un premio pecuniario con cargo a los presupuestos municipales o provinciales encaja en el concepto de subvención que allí se recoge ${ }^{2}$. La propia LGS prevé, en una disposición adicional, que reglamentariamente se establecerá el régimen especial aplicable al otorgamiento de los premios educativos, culturales o científicos. De momento, el Gobierno no ha encontrado el momento oportuno para establecerlo, pero ello no obsta a la aplicación de las disposiciones de la ley.

Muchos de los ayuntamientos y diputaciones que conceden premios ignoran olímpicamente los preceptos legales. Ignoran, no en el sentido de que no tengan noticia de su existencia, tienen obligación de conocerla desde el momento en que se publican en el correspondiente boletín oficial, sino en el segundo sentido que da el DRAE al verbo ignorar: «No hacer caso de algo o de alguien, o tratarlos como si no merecieran atención». Aunque cada vez sean más los que van adecuándose a la LGS, contrastar las bases de las convocatorias de premios literarios que casi a diario se publican por los ayuntamientos y diputaciones de nuestro país con las disposiciones legales todavía resulta descorazonador. Como veremos, no hablamos de casos aislados, ni de ayuntamientos de pequeñas y remotas poblaciones que carecen de adecuado asesoramiento jurídico, ni de premios con cuantías insignificantes.

\section{PUBLICIDAD Y PUBLICACIÓN}

La convocatoria de un premio literario, abierto a la concurrencia de escritores, ha de ser pública, por supuesto, y no solo porque lo diga la ley, que lo dice ${ }^{3}$, sino porque lo dicta la lógica. El organismo otorgante ha de hacer saber a los posibles interesados que se abre la convocatoria para que puedan presentar sus obras. Y, sí, todos los ayuntamientos o diputaciones que convocan premios les dan algún tipo de publicidad. Cuando menos, lo hacen a través de su página web, y con frecuencia también mediante notas o ruedas de prensa, para que se hagan eco los medios de comunicación, y a veces hasta publican anuncios en la prensa.

Pero la LGS exige algo más, que demasiadas entidades locales no cumplen. Su art. 18 dispone que las administraciones concedentes deberán remitir información sobre las convocatorias y las resoluciones de concesión recaídas a la Base de Datos Nacional de Subvenciones (BDNS), que es mantenida por la Intervención General de la Administración del Estado, dependiente del Ministerio de Hacienda, y cualquier persona puede consultar ${ }^{4}$. Antes de la convocatoria deben aprobarse las bases reguladoras de concesión, normas de carácter reglamentario en desarrollo de la ley que las entidades locales pueden incluir en una ordenanza o en sus presupuestos, y dichas bases deben publicarse en el diario oficial correspondiente. No son pocas las entidades locales que prescinden de ello y aprueban directamente las convocatorias de premios y subvenciones o los actos de concesión nominativa. También la convocatoria, al menos en extracto, ha de publicarse en el correspondiente diario oficial, en el caso de los ayuntamientos y diputaciones el de la

2 Art. 2.1 de la LGS: «Se entiende por subvención, a los efectos de esta ley, toda disposición dineraria realizada por cualesquiera de los sujetos contemplados en el artículo 3 de esta ley, a favor de personas públicas o privadas, y que cumpla los siguientes requisitos:

a) Que la entrega se realice sin contraprestación directa de los beneficiarios.

b) Que la entrega esté sujeta al cumplimiento de un determinado objetivo, la ejecución de un proyecto, la realización de una actividad, la adopción de un comportamiento singular, ya realizados o por desarrollar, o la concurrencia de una situación, debiendo el beneficiario cumplir las obligaciones materiales y formales que se hubieran establecido.

c) Que el proyecto, la acción, conducta o situación financiada tenga por objeto el fomento de una actividad de utilidad pública o interés social o de promoción de una finalidad pública».

3 Art. 8.3 de la LGS: «La gestión de las subvenciones a que se refiere esta ley se realizará de acuerdo con los siguientes principios: a) Publicidad, transparencia, concurrencia, objetividad, igualdad y no discriminación (...)».

4 https://www.pap.hacienda.gob.es/bdnstrans/ge/es/convocatorias. 
provincia o de la comunidad autónoma uniprovincial ${ }^{5}$. En los últimos años cada vez más entidades locales remiten sus convocatorias a la BDNS y las publican en un diario oficial, pero muchas otras siguen prescindiendo de estos trámites ${ }^{6}$.

Por otro lado, el principio de publicidad no se limita al acto de la convocatoria, sino que, junto al de transparencia, debe presidir todo el procedimiento de concesión del premio. Con frecuencia, la tramitación adquiere un carácter casi secreto, prima la costumbre de que se oculte tanto la personalidad de los aspirantes al premio como la de quienes han de juzgar sus méritos. Si los defectos en la publicación solo afectan a la eficacia de la convocatoria, los de transparencia pueden afectar a la validez de los actos del procedimiento.

\section{IGNOTOS CONCURSANTES}

Es tradicional en los premios literarios, aunque no sucede siempre, que los participantes en la convocatoria envíen sus obras bajo seudónimo, de modo que el jurado que ha de juzgarlas, supuestamente, resuelva con mayor objetividad e imparcialidad, y que una vez emitido el fallo se abra la plica donde figuran los datos del autor de la obra u obras premiadas. Lo mismo se suele hacer por los ayuntamientos y diputaciones convocantes, con cláusulas como las siguientes: «Los trabajos irán sin firma, ni dato alguno que pueda desvelar la autoría del mismo»; «Los trabajos se remitirán exclusivamente por correo electrónico a ...@... indicando en el asunto del mensaje, el nombre del certamen. En dicho e-mail se adjuntarán dos archivos. En el primero, figurará la obra a concurso sin nombre del autor. Y en el segundo, los datos del autor: nombre y apellidos, edad, domicilio, teléfono, correo electrónico y breve reseña biográfica» ${ }^{7}$. El concursante ha de confiar en que el segundo archivo no será examinado antes de tiempo o por quien no deba.

El sistema de plicas cerradas, para proteger la identidad de los participantes en un procedimiento administrativo de modo que el órgano que conoce del mismo adopte su valoración o dictamen sin conocerla, no está proscrito por la ley, al contrario, es abundantemente utilizado por las Administraciones Públicas en los procedimientos de selección de personal y de contratación pública. Es usual que los exámenes de una oposición se entreguen de forma anónima bajo plica, o que los trabajos que se presentan a un concurso de proyectos se sometan a un jurado de forma anónima ${ }^{8}$. Solo una vez otorgadas las correspondientes puntuaciones, se abren las plicas para adjudicarlas a las personas a quienes correspondan.

Pero eso es una cosa, y otra es el anonimato de los interesados durante todo el procedimiento, e incluso más allá, y ante todos los órganos administrativos, lo cual sí está legalmente proscrito. No cabe un procedimiento administrativo por completo anónimo y secreto, en el cual la Administración no identifica a los interesados ni sabe con quién está tratando ${ }^{9}$. Aunque, en apariencia, el anonimato protege al concursante, se vuelve en su contra desde el momento en que le veda cualquier comunicación con la Administración convocante. No va a ser notificado de ninguno de los trámites del procedimiento, ni siquiera si le afectan de forma directa y negativa, por ejemplo, si su obra es excluida por alguna cuestión formal. Como norma general,

5 Art. 9.2 de la LGS: «Con carácter previo al otorgamiento de las subvenciones, deberán aprobarse las normas que establezcan las bases reguladoras de concesión en los términos establecidos en esta ley. Las bases reguladoras de cada tipo de subvención se publicarán en el Boletín Oficial del Estado o en el diario oficial correspondiente». Art. 17.3 de la LGS: «La norma reguladora de las bases de concesión de las subvenciones concretará, como mínimo, los siguientes extremos: (...) diario oficial en el que se publicará el extracto de la convocatoria».

6 Como ejemplos recientes, la convocatoria de la XL edición del Premio Literario de Novela y Narración Corta Felipe Trigo (20.000 y 6.500 euros, respectivamente) del Ayuntamiento de Villanueva de la Serena (Badajoz), publicada en la web municipal, pero no en la BDNS ni en el Boletín Oficial de la Provincia de Badajoz; la convocatoria del Premio de Novela Café Gijón (20.000 euros), del Ayuntamiento de Gijón (Asturias), sí fue publicada en el Boletín Oficial del Principado de Asturias núm. 31 , de 14 de febrero de 2020, pero no aparece en la BDNS; la convocatoria de la 67 Edición del Premio de Novela Ateneo-Ciudad de Valladolid (20.000 euros) del Ayuntamiento de Valladolid, aparece en la BDNS, pero no en el Boletín Oficial de la Provincia de Valladolid.

7 Apartado 4 de la convocatoria del III Certamen de Poesía Villa de Ágreda 2020 (600 euros), aprobada por el Ayuntamiento de Ágreda (Soria) y publicada solo a través de las redes sociales.

8 Art. 187 de la Ley 9/2017, de 8 de noviembre, de Contratos del Sector Público (LCSP), sobre los concursos de proyectos: «El jurado adoptará sus decisiones o dictámenes con total autonomía e independencia, sobre la base de proyectos que le serán presentados de forma anónima»; "Se entenderá por proyectos presentados de forma anónima aquellos en los que no solo no figure el nombre de su autor, sino que además no contengan datos o indicios de cualquier tipo que permitan conocer indirectamente la identidad del autor o autores del mismo».

9 Art. 9.1 de la Ley 39/2015, de 1 de octubre, del Procedimiento Administrativo Común de las Administraciones Públicas (LPAC): «Las Administraciones Públicas están obligadas a verificar la identidad de los interesados en el procedimiento administrativo, mediante la comprobación de su nombre y apellidos o denominación o razón social, según corresponda, que consten en el Documento Nacional de Identidad o documento identificativo equivalente». 
si el interesado en cualquier procedimiento administrativo incumple algún requisito al presentar su solicitud o escrito de iniciación, la Administración ha de advertirle de ello y darle un plazo para que pueda subsanar el defecto ${ }^{10}$. El concursante anónimo se convierte en un convidado de piedra del procedimiento, en completa indefensión. Con suerte, solo tendrá noticias sobre este a través de los medios de comunicación cuando se conceda el premio. No tendrá conocimiento de qué ha sucedido con su obra, si ha sido o no admitida, no se le concederá la posibilidad de hacer ninguna subsanación y lo tendrá francamente difícil para, en su caso, recurrir la decisión final; ni siquiera puede acreditar que es interesado porque ha presentado una obra, ya que es frecuente que no se abran las plicas de las obras no premiadas y que sean destruidas junto con estas. "La plica solo se abrirá en caso de que la obra resulte ganadora» ${ }^{11}$, indican algunas convocatorias, y en otros casos son todavía más terminantes: «El Secretario abrirá únicamente la plica de la obra que resulte premiada. Los otros autores finalistas continuarán siendo anónimos para los convocantes» ${ }^{12}$.

Es perfectamente posible, y ajustado a la ley, establecer que las obras sean presentadas con seudónimo y que el jurado o, en su caso, la comisión que previamente seleccione de entre todas las presentadas las que se someterán a consideración del jurado, las examine sin tener constancia de la identidad de sus autores. Ello no es incompatible con que los participantes estén identificados ante la entidad convocante. La naturaleza del procedimiento se puede mantener siempre y cuando los funcionarios que se encarguen de tramitar el expediente guarden la oportuna reserva, del mismo modo en que está regulado para los concursos de proyectos ya mencionados. En tal sentido, cabe poner como ejemplo la convocatoria del XLVI Premio Ciutat d'Alcoi de Teatro Pep Cortés $2020^{13}$. Los participantes no son anónimos, las obras dramáticas han de presentarse acompañadas de un documento con la identificación del autor y de una declaración responsable de estar al corriente en las obligaciones tributarias y de la Seguridad Social. Pero se añade:

«Estos dos documentos añadidos no se enviarán al Jurado, de modo que quedará resguardada la identidad de quienes presenten obras al certamen, con la excepción de quien finalmente obtenga el galardón y esto solamente en el momento en que ya se haya adoptado formalmente la decisión de cuál es la obra premiada.

De la custodia de estos datos se responsabiliza la oficina de organización del Premio, es decir, el Departamento de Cultura del Ayuntamiento de Alcoy».

Otro ejemplo, de momento no muy seguido pero que constituye una buena referencia para otras entidades y también para el futuro reglamento de desarrollo de la LGS, es el de la XLVI Edición del Premio Nacional de Poesía Antonio González de Lama convocado por el Ayuntamiento de León ${ }^{14}$ :

«- La forma de presentación de las obras se hará a través de la sede electrónica de la página web del Ayuntamiento de León, en el apartado PREMIO DE POESÍA ANTONIO GONZÁLEZ DE LAMA de Cultura, dentro de los Trámites on line (enlace: https://sede.aytoleon.es/ GDCarpetaCiudadano/login.do) en formato pdf.

- El procedimiento para la presentación de las obras será el siguiente:

- Al acceder a la inscripción en el Premio (mediante el sistema descrito en el párrafo anterior) se solicitará del autor un Lema (título de la obra) y un Pseudónimo, además de adjuntar el propio pdf con el poemario, que serán los datos y archivo que llegarán al jurado que emitirá el fallo final.

- Se le requerirá, además, que descargue y cumplimente un documento en el que figurarán todos sus datos personales (nombre, apellidos, dirección, $n .^{\circ}$ de teléfono/s, dirección

10 Art. 68.1 de la LPAC: «Si la solicitud de iniciación no reúne los requisitos que señala el artículo 66, y, en su caso, los que señala el artículo 67 u otros exigidos por la legislación específica aplicable, se requerirá al interesado para que, en un plazo de diez días, subsane la falta o acompañe los documentos preceptivos, con indicación de que, si así no lo hiciera, se le tendrá por desistido de su petición». En el mismo sentido, el art. 23.5 de la LGS.

11 Apartado 9 de la convocatoria de la XXXVIII edición de los Premios Literarios Ciutat de València (ocho modalidades con un total de 72.000 euros), aprobada por el Ayuntamiento de Valencia (Boletín Oficial de la Provincia de Valencia núm. 110 , de 10 de junio de 2020).

12 Apartado 7 de la convocatoria del VII Premio de Novela Corta de Terror Ciudad de Utrera (2.000 euros), aprobada por el Ayuntamiento de Utrera (Sevilla), se publica únicamente en la página web de la Editorial Premium.

13 Boletín Oficial de la Provincia de Alicante núm. 116, de 19 de junio de 2020. La dotación es de 8.000 euros.

14 Boletín Oficial de la Provincia de León núm. 88, de 15 de mayo de 2020. La dotación es de 6.000 euros. 
de correo electrónico, nacionalidad y una breve nota bibliográfica) y que adjunte una copia de su DNI o documento similar de identidad en el caso de no ser de nacionalidad española. Para garantizar el anonimato del autor, toda esta información quedará encriptada automáticamente en los servidores del Ayuntamiento de León, y la persona que opte al Premio podrá descargarse el resguardo de su inscripción.

- Solo el mismo día y momento del fallo del jurado, y en presencia de los miembros que lo componen, se solicitará a los servicios informáticos del propio Ayuntamiento de León, la clave para el descifrado de la información personal de la persona ganadora del Premio (y solo de esa persona)».

Pese a su evidente ilegalidad, son muchas las convocatorias que convierten el procedimiento de concesión del premio en anónimo y secreto. Aunque hay algún caso incluso peor, en el que los participantes no son anónimos pero se les niegan sus derechos más básicos, como el de ser notificados de las resoluciones que les afectan para poder defender sus intereses ${ }^{15}$. Se pueden encontrar cláusulas como esta: «El envío de la obra por cualquier otro medio que no sea la página web indicada, fuera de plazo, siendo defectuosa, faltando parte de la información o cualquiera de los ficheros que obligatoriamente han de ser adjuntados será causa automática de exclusión sin comunicación alguna al interesado» ${ }^{16}$. Y aunque nada se prevea en las convocatorias, suele ser práctica habitual que las entidades convocantes, no solo no se comuniquen con los interesados, sino tampoco con la ciudadanía en general; no se suele hacer pública la relación de obras presentadas, únicamente su número, a menudo tampoco las que efectivamente son sometidas a conocimiento del jurado, ni la puntuación o los votos que reciben. La aversión que muestran algunas entidades locales a mezclarse con el populacho y a asumir cualquier obligación se pone de relieve en cláusulas como estas:

«No se mantendrá correspondencia con los autores de las obras presentadas, ni se proporcionará información sobre la clasificación y valoración de las novelas» ${ }^{17}$.

«No hay obligación de dar recibos u otros documentos de las obras debidamente presentadas al premio ni de sostener correspondencia o comunicación alguna con los participantes, ni facilitar a estos información sobre clasificación de las novelas. Con relación a los originales remitidos a este premio no se adquiere responsabilidad ni obligación alguna. Las entidades organizadoras no se hacen responsables de las eventuales pérdidas o deterioros de los originales, ni de los retrasos, o cualesquiera otras incidencias imputables a correos o a terceros, que puedan afectar a los envíos de las obras participantes en el Premio» ${ }^{18}$.

\section{EL JURADO, ESE GRAN DESCONOCIDO}

Casi tan misteriosos como los concursantes suelen ser los jurados. Rara vez los miembros del jurado son designados en la propia convocatoria, o se hace público su nombramiento antes de la fiesta de entrega del premio, a veces ni siquiera entonces. Son usuales cláusulas como la siguiente: «Los miembros del jurado se darán a conocer el día del fallo. El premio será otorgado por votación de un jurado de cinco miembros relacionados con la literatura, designados libremente por el Ayuntamiento de Soria y uno de ellos por la editorial que se encargue de su publicación» ${ }^{19}$. En esto la práctica de las entidades locales se aleja notablemente de la que siguen con cualquier otro tipo de convocatorias, donde sí se sabe quiénes van a tomar las decisiones, atendiendo al derecho que tienen los ciudadanos de conocer la identidad de las personas que

15 Art. 40.1 de la LPAC: «El órgano que dicte las resoluciones y actos administrativos los notificará a los interesados cuyos derechos e intereses sean afectados por aquéllos».

16 Apartado 4 de la convocatoria del XII Premio Málaga de Ensayo (6.000 euros), aprobada por el Ayuntamiento de Málaga (Boletín Oficial de la Provincia de Málaga núm. 127, de 3 de julio de 2020).

17 Base sexta de la convocatoria del I Premio Ciudad de Estepona de Novela (25.000 euros), aprobada por el Ayuntamiento de Estepona (Málaga) y publicada en su página web y en la de las entidades colaboradoras Fundación Manuel Alcántara y Editorial PreTextos.

18 Apartado 6 de la convocatoria del XIX Premio Carolina Coronado de Novela Ciudad de Almendralejo (8.000 euros), aprobada por el Ayuntamiento de Almendralejo (Badajoz), publicada en la página web municipal.

19 Apartado e) de la convocatoria de la 7. a edición del Premio Avelino Hernández de Novela Juvenil (6.000 euros), aprobada por el Ayuntamiento de Soria y publicada en la página web municipal. 
tienen la potestad de condicionar sus vidas y sus intereses ${ }^{20}$. A nadie se le ocurre que pueda tramitarse una oposición sin que los opositores sepan desde el principio quiénes componen el tribunal calificador; y lo propio sucede con una mesa de contratación, con una comisión de valoración de subvenciones o con el jurado del concurso de carteles de las fiestas patronales. En cambio, parece que con los premios literarios resulta todavía aceptable un secretismo más propio de El proceso de Kafka o, aunque los miembros de los jurados no suelan ir encapuchados, de las causas del Tribunal del Santo Oficio.

Además del derecho a conocer a los miembros del jurado, los participantes en la convocatoria de un premio tienen derecho a recusarlos si concurre alguno de los motivos que establece la ley para asegurar su imparcialidad. Hay alguna convocatoria que así lo recuerda expresamente:

«2. Quienes actúen como miembros del Jurado deberán abstenerse de intervenir cuando en ellos concurra alguna de las causas previstas en el art. 23 de la Ley 40/2015, de 1 de octubre, del Régimen Jurídico del Sector Público.

3. Asimismo, las personas interesadas podrán promover la recusación de miembros del Jurado en los casos previstos en el párrafo anterior, de conformidad a lo establecido en el art. 24 de la citada Ley» ${ }^{21}$.

Es obvio que resulta imposible recusar a los miembros del jurado si se desconoce quiénes son hasta después de que el premio haya sido otorgado. Sería teóricamente posible ejercer el derecho de recusación si el concursante suspicaz se dirigiera a la entidad local convocante para preguntar sobre la composición del jurado. Pero la mayoría de las convocatorias ponen coto a tal iniciativa; ya hemos mencionado la habitual cláusula en la cual las entidades locales se niegan a mantener cualquier correspondencia con los concursantes (que ni siquiera pueden acreditar que lo sean, dado que sus plicas permanecen cerradas), en flagrante infracción de sus derechos reconocidos por la ley ${ }^{22}$. Añadamos que, cuando la hay, tampoco se suele informar de la composición de la comisión lectora que hace una selección previa de las obras que examinará el jurado.

\section{LA ADMINISTRACIÓN PREELECTRÓNICA}

Hace años que nuestros gobernantes están empeñados en que las Administraciones Públicas incorporen a su funcionamiento habitual las nuevas tecnologías de la información y comunicación, que no pasa solo por dotar de un ordenador a cada funcionario sino a que la tramitación de los expedientes se haga de forma electrónica, desterrando progresivamente las montañas de papel típicas de las dependencias administrativas. Uno de los hitos en este salto a la modernidad fue la Ley 30/1992, de 26 de noviembre, de Régimen Jurídico de las Administraciones Públicas y del Procedimiento Administrativo Común, cuyo art. 45 disponía que «las Administraciones Públicas impulsarán el empleo y aplicación de las técnicas y medios electrónicos, informáticos y telemáticos, para el desarrollo de su actividad y el ejercicio de sus competencias»; posteriormente, la Ley 11/2007, de 22 de junio, de acceso electrónico de los ciudadanos a los Servicios Públicos, apodada como «Ley de la Administración Electrónica», introdujo «el derecho de los ciudadanos a relacionarse con las Administraciones Públicas por medios electrónicos», y la vigente LPAC de 2015 da el paso definitivo de considerar los medios electrónicos como los habituales en el funcionamiento y en las comunicaciones de las Administraciones Públicas implantando las sedes electrónicas, los registros electrónicos, los expedientes electrónicos, las firmas electrónicas, los archivos electrónicos, etc. Su preámbulo afirma que «una Administración sin papel basada en un funcionamiento íntegramente electrónico no sólo sirve mejor a los principios

20 Art. 53.1 de la LPAC: «Además del resto de derechos previstos en esta Ley, los interesados en un procedimiento administrativo, tienen los siguientes derechos: (...) b) A identificar a las autoridades y al personal al servicio de las Administraciones Públicas bajo cuya responsabilidad se tramiten los procedimientos».

21 Base VII de la convocatoria de la LI edición de los Premios Ciudad de Alcalá 2020 (que, entre otros, incluye uno de narrativa y otro de poesía de 6.000 euros cada uno), aprobada por el Ayuntamiento de Alcalá de Henares (Boletín Oficial de la Comunidad de Madrid núm. 165, 9 de julio de 2020).

22 Art. 53.1: «Además del resto de derechos previstos en esta Ley, los interesados en un procedimiento administrativo, tienen los siguientes derechos: a) A conocer, en cualquier momento, el estado de la tramitación de los procedimientos en los que tengan la condición de interesados; el sentido del silencio administrativo que corresponda, en caso de que la Administración no dicte ni notifique resolución expresa en plazo; el órgano competente para su instrucción, en su caso, y resolución; y los actos de trámite dictados. Asimismo, también tendrán derecho a acceder y a obtener copia de los documentos contenidos en los citados procedimientos (...)». 
de eficacia y eficiencia, al ahorrar costes a ciudadanos y empresas, sino que también refuerza las garantías de los interesados». La implantación de una Administración totalmente electrónica ha sufrido algún pequeño retraso. Inicialmente se preveía que la LPAC entraba en vigor en octubre de 2016, salvo las previsiones relativas al registro electrónico de apoderamientos, el registro electrónico, el registro de empleados públicos habilitados, el punto de acceso general electrónico de la Administración y el archivo único electrónico, que por las dificultades técnicas que entraña su cumplimiento producirían efectos a partir de octubre de 2018; a punto de cumplirse tal plazo, se prorrogó hasta octubre de 2020; y luego, con una pandemia como motivo, o como excusa, hasta abril de 2021.

Aunque sigue pendiente la culminación de convertir a nuestras Administraciones Públicas en totalmente electrónicas, en los últimos años la mayoría de ellas han recorrido casi todo el camino. Hoy ya es usual que los ciudadanos podamos presentar nuestras instancias en un registro electrónico, que a través de la página web de un ayuntamiento, una diputación, un gobierno autonómico o un ministerio podamos acceder con comodidad a multitud de trámites electrónicos, desde pagar una multa de tráfico hasta pedir un certificado de empadronamiento, y que las resoluciones administrativas se firmen electrónicamente.

De este imparable avance de los electrones en nuestra vida ordinaria, de momento, quedan excluidos buena parte de los premios literarios municipales y provinciales, anclados en la era preelectrónica. Incluso aunque sean convocados por ayuntamientos y diputaciones que cuentan con magníficas sedes electrónicas de uso común y habitual, siguen mostrando un fervoroso apego al papel. Ignorando el derecho de los ciudadanos, entre los que también están comprendidos los escritores, a relacionarse electrónicamente con la Administración ${ }^{23}$, introducen en las convocatorias la obligación de presentar sus obras en papel y a través de cauces preelectrónicos como el correo postal. Son usuales cláusulas como las siguientes: «Los trabajos que concursen habrán de ser inéditos y tener una extensión de 125 a 250 páginas, tamaño DIN A-4, impresas con letra Times New Roman 12, con interlineado de 1,5 mm, paginados, encuadernados o cosidos y por triplicado» ${ }^{24}$; "Se presentarán cinco ejemplares, mecanografiados, en papel tamaño DIN A-4, mecanografiados por una sola cara, a doble espacio, en letra Arial o New Roman 12, y debidamente grapados, cosidos o encuadernados ${ }^{25}$. Hay que agradecer que ya no se exija pegar una póliza en cada ejemplar. Hay algún ayuntamiento que dispone de sede electrónica y cuyos órganos firman electrónicamente la convocatoria de un premio literario cuyas bases resultan completamente analógicas: «Las obras serán presentadas o enviadas hasta el 15 de Octubre 2020: a) por correo certificado a la CONCEJALíA DE CULTURA (...). b) en oficinas del Ayuntamiento, Registro General de lunes a viernes de 8,30 horas a 14,30 horas» ${ }^{26}$.

El apego al soporte de celulosa se pone de relieve incluso cuando los ayuntamientos, muy a su pesar, se ven obligados a recurrir a medios electrónicos: «Excepcionalmente en esta edición de 2020, por la situación generada por la Covid 19, además del correo ordinario, se aceptarán originales enviados por correo electrónico (formato PDF) » ${ }^{27}$. Quizás, pasada la pandemia, se pueda volver al añorado sistema de toda la vida, aunque las leyes se empeñen en decir otra cosa.

Algún Ayuntamiento se apunta a la tramitación electrónica, pero a tiempo parcial. Permite la presentación de las obras a través de su sede electrónica, adjuntando a la instancia el fichero con la obra en formato digital, pero seguidamente añade: «Aquellos concursantes que envíen su novela a través de internet y participen con seudónimo, deberán remitir además por correo postal una plica o sobre cerrado, con el seudónimo y título en el exterior, y con los datos identificativos (nombre, apellidos, dirección y teléfono) en

23 Art. 13 de la LPAC: «Quienes de conformidad con el artículo 3, tienen capacidad de obrar ante las Administraciones Públicas, son titulares, en sus relaciones con ellas, de los siguientes derechos: a) A comunicarse con las Administraciones Públicas a través de un Punto de Acceso General electrónico de la Administración. b) A ser asistidos en el uso de medios electrónicos en sus relaciones con las Administraciones Públicas (...)». Art. 14.1: «Las personas físicas podrán elegir en todo momento si se comunican con las Administraciones Públicas para el ejercicio de sus derechos y obligaciones a través de medios electrónicos o no, salvo que estén obligadas a relacionarse a través de medios electrónicos con las Administraciones Públicas. El medio elegido por la persona para comunicarse con las Administraciones Públicas podrá ser modificado por aquella en cualquier momento».

24 Base 2. ${ }^{a}$ de la convocatoria del Premio Camilo José Cela de Narrativa (6.200 euros), que forma parte de los Premios Provincia de Guadalajara y Río Ungría y Río Henares-2020 convocados por la Diputación de Guadalajara (Boletín Oficial de la Provincia de Guadalajara núm. 177, de 17 de septiembre de 2020).

25 Base cuarta de la convocatoria del XXI Premio de Novela Corta (12.000 euros) de la Diputación de Córdoba (Boletín Oficial de la Provincia de Córdoba núm. 129, de 8 de julio de 2020).

26 Apartado 4 de la convocatoria del XXVIII Concurso de Prosa 2020 (250 euros), aprobada por el Ayuntamiento de Los Molinos (Madrid) y publicada en la página web municipal.

27 Base 2 de la convocatoria del XXXIII Certamen Poético Ángel Martínez Baigorri (1.000 euros), aprobada por el Ayuntamiento de Lodosa (Navarra) y publicada solo a través de su página web. 
el interior, a la dirección más abajo indicada» ${ }^{28}$. Es difícil dejar la adicción al papel de golpe. Otra aproximación a los tiempos modernos, pero sin exagerar, aparece en muchas convocatorias en las cuales, además de uno o varios ejemplares en papel, se exige también una copia digital de la obra que también tiene que ser enviada por correo postal o con un mensajero a lomos del Pony Express: «De cada original se remitirán dos copias en papel y otra en soporte digital (Word, Open Word, PDF o compatibles). No se aceptarán envíos por correo electrónico» ${ }^{29}$. Hay alguna convocatoria donde las obras se presentan en formato digital, por correo electrónico, pero en la que, una vez hecha una primera criba por el jurado, se exige el regreso al papel: «Los autores de los originales seleccionados serán requeridos por el Ayuntamiento de Santander mediante correo electrónico para que envíen una copia impresa de la obra antes del 1 de septiembre de 2018. Quienes no atendieren en tiempo y forma a dicho requerimiento quedarán automáticamente excluidos de la selección» ${ }^{30}$.

La práctica de solicitar varios ejemplares del mismo documento, en papel o en formato digital, o en ambos, se comparece mal con la ley. Hace muchos años que los legisladores intentan, además de implantar la Administración electrónica, no incordiar al ciudadano exigiendo copias y más copias de papeles que ya tiene. Es muy cómodo para los funcionarios no tener que rebuscar por los archivos ni hacer fotocopias y que sea el interesado el que aporte una y otra vez copias de su DNI, de su declaración del IRPF, de su libro de familia, de su certificado de empadronamiento, de su título de EGB. La ley dice con claridad que todo ciudadano tiene derecho a que la Administración no le maree pidiéndole documentos que ya tiene ${ }^{31}$. Si la Administración dispone de un ejemplar en papel de la novela presentada a concurso, no tiene porqué pedir otro digital; y si tiene ya el archivo electrónico, no tiene porqué pedir otro ejemplar impreso y, además, encuadernado. Pero es complicado apear a la Administración de sus prácticas. Mientras haya premios literarios, hay futuro para el sector de la fotocopia y el canutillo.

\section{UNO DE LOS NUESTROS}

La mayoría de los premios literarios están abiertos a la participación de autores de cualquier nacionalidad y que tengan residencia en cualquier lugar, solo se les exige que escriban en una determinada lengua. Pero hay algunos que limitan la participación a los escritores indígenas. Así, por ejemplo: «Podrán participar en este certamen los escritores y escritoras que inician su experiencia literaria, nacidos en la provincia de Jaén o residentes en ella» 32 ; o, sin incluir tal requisito de forma expresa, se deduce que se va a exigir ya que los participantes han de presentar «fotocopia del D.N.I. y documento que acredite su sorianidad» ${ }^{33}$.

Exigir un origen, nacionalidad o vecindad determinados chirría con los principios de igualdad y no discriminación que deben presidir el otorgamiento de los premios. Cualquier requisito que limite el acceso a una subvención debe tener una justificación objetiva y razonable para no convertirse en una discriminación proscrita por la ley ${ }^{34}$. Es comprensible el deseo de las entidades locales de reconocer y promocionar a sus vecinos, pero cuando se hace mediante prestaciones económicas debe justificarse de forma adecuada la finalidad de la subvención o premio y la razón por la cual se introduce un determinado requisito, y ello se debe hacer en las bases reguladoras debidamente aprobadas previamente a la convocatoria y publicadas

28 Base 3 de la citada convocatoria del Premio de Novela Café Gijón.

29 Apartado 3 de la citada convocatoria de la 67 Edición del Premio de Novela Ateneo-Ciudad de Valladolid.

30 Base séptima de la convocatoria de la 11. a edición del Premio Tristana de Novela Fantástica (6.000 euros), aprobada por el Ayuntamiento de Santander (Boletín Oficial de Cantabria núm. 59, 23 de marzo de 2018).

31 Art. 53.1 de la LPAC: «Además del resto de derechos previstos en esta Ley, los interesados en un procedimiento administrativo, tienen los siguientes derechos: (...) d) A no presentar datos y documentos no exigidos por las normas aplicables al procedimiento de que se trate, que ya se encuentren en poder de las Administraciones Públicas o que hayan sido elaborados por éstas».

32 Convocatoria del XXX Concurso Premio Escritores Noveles (2.000 euros) de la Diputación de Jaén (Boletín Oficial de la Provincia de Jaén núm. 143, de 28 de julio de 2020).

33 Base tercera de la convocatoria del V Premio de Microrrelatos y Microvídeos 2020 (cinco premios por un total de 1.200 euros) de la Diputación de Soria, publicada únicamente en su página web.

34 Sentencia del Tribunal Supremo de 13 de octubre de 1998: «La subvención, como toda técnica de fomento, introduce un elemento de diferenciación en cuanto que con ella se potencia con determinados beneficios una concreta actividad privada que se adecua a ciertos objetivos perseguidos por la Administración otorgante de la subvención. Sin embargo, ello no supone una discriminación contraria al artículo $14 \mathrm{CE}$, siempre que exista una razón jurídicamente atendible que justifique esa diferencia de trato y que, en el ámbito de que se trata, se traduce en la legitimidad de la finalidad perseguida por la Administración y en la ausencia de desproporción en el mecanismo de fomento utilizado». 
tanto en la BDNS como en el correspondiente diario oficial, cosa que, como ya hemos dicho, no siempre se hace ${ }^{35}$. Por otro lado, cuando se introducen, esos requisitos deben ser claros y objetivos; lo son las exigencias sobre lugar de nacimiento o residencia, pero mucho más dudosamente las que se refieren al incierto concepto de «sorianidad».

\section{AMIGOS PARA SIEMPRE}

Las convocatorias de premios literarios, con mucha frecuencia, exigen a los participantes una lealtad absoluta, que no presenten sus obras a ningún otro concurso. Son muy usuales cláusulas como esta: «Las novelas deberán ser originales e inéditas, escritas en Lengua Española, no estar comprometidas con ninguna editorial y no haber sido premiadas ni estar presentadas a otro concurso pendiente de fallo» ${ }^{36}$.

Ninguna norma legal restringe la libertad para presentar una obra a varios premios, o de solicitar subvención para una misma actividad a varias entidades. La única limitación que resulta legal es exigir que, si el autor recibe otro premio para la misma obra, deba comunicarlo a la entidad local ${ }^{37}$. Por eso hay otras convocatorias de premios que, más prudentemente, insertan requisitos como el siguiente: «Los poemarios han de estar escritos en castellano, ser originales, inéditos y sus poemas no haber sido premiados ni incluidos en ningún otro libro o certamen, obligándose el poeta a retirar su original si éste hubiera conseguido previamente algún galardón ${ }^{38}$.

Pero, además de abusiva, la cláusula de exclusividad resulta ridícula e ineficaz. A menudo, son los mismos ayuntamientos convocantes que exigen total anonimato a los participantes los que pretenden prohibirles que concurran a otros premios con la misma obra. Si no sabe quiénes son los autores que han presentado sus obras, solo conoce sus seudónimos, les veda cualquier comunicación con el Ayuntamiento y no piensa abrir las plicas de las obras no ganadoras, resulta totalmente imposible que la entidad local convocante pueda saber si esas obras se han presentado a otros certámenes. Solo podrá enterarse a través de la prensa, igual que los autores se enteran de estas cosas, de que una obra con el mismo título ha sido premiada en otro concurso. Sin abrir la plica, ni siquiera tendrá la seguridad de que se trate del mismo autor. Y, suponiendo que pudiera confirmar que es la misma obra, lo único que puede hacer es excluirla de su propio premio, lo cual al interesado, que ya ha visto su obra premiada en otra parte, le traerá sin cuidado. Los escritores suelen ser conscientes de estas circunstancias y hacen caso omiso de la prohibición de presentar sus obras a varios premios a la vez.

Pero los celos de algunas entidades locales y su pretensión de garantizar una relación de absoluta fidelidad por parte de los participantes en los premios literarios van más allá. También es usual una cláusula como la siguiente: «La participación en el Premio implica la aceptación de todas y cada una de las bases, el compromiso del autor de no retirar la obra antes del fallo y aceptar el premio si le fuera concedido, así como participar con su presencia en el acto de entrega del mismo» ${ }^{39}$. Se trata de una disposición sin ningún respaldo legal. Todo interesado en un procedimiento administrativo, incluyendo el de concesión de un premio literario, tiene derecho a desistir en el momento en que le parezca oportuno, y cualquier persona puede renunciar a cualquiera de sus derechos, incluido el de recoger un premio literario ${ }^{40}$.

35 Sentencia del Tribunal Superior de Justicia de Madrid núm. 365/2018, de 29 de junio: «Así las cosas, la Orden recurrida (...) no fundamenta ni justifica, ni de forma somera, la razón del requisito de que para ser contratado por los beneficiarios directos de la subvención haya que tener la residencia en los municipios de la Comunidad de Madrid. Se afirma en el escrito de contestación a la demanda que la Orden se dicta a los efectos de una mejora del empleo en la Región. Sin embargo, como hemos dicho, ni en la Orden ni en ningún otro informe se consigna de forma expresa que esa haya sido la finalidad de la misma. Así pues, el requisito establecido en el artículo de la Orden recurrida no está motivado ni fundamentado y ello determina la estimación del presente recurso».

36 Convocatoria del V Premio de Narrativa Carmen Martín Gaite 2020 (5.000 euros), aprobada por el Ayuntamiento de El Boalo (Madrid), publicada únicamente en la página web municipal.

37 En este caso parece aplicable por analogía lo que dispone el art. 14.1 de la LGS: «Son obligaciones del beneficiario: (..) $d$ ) Comunicar al órgano concedente o la entidad colaboradora la obtención de otras subvenciones, ayudas, ingresos o recursos que financien las actividades subvencionadas. Esta comunicación deberá efectuarse tan pronto como se conozca y, en todo caso, con anterioridad a la justificación de la aplicación dada a los fondos percibidos».

38 Base 2 de la convocatoria del XXII Premio de Poesía Nicolás del Hierro 2020 (1.800 euros), aprobada por el Ayuntamiento de Piedrabuena (Ciudad Real) y publicada únicamente en su página web.

39 Base séptima de la citada convocatoria del I Premio Ciudad de Estepona de Novela.

40 Art. 94.1 de la LPAC: «Todo interesado podrá desistir de su solicitud o, cuando ello no esté prohibido por el ordenamiento jurídico, renunciar a sus derechos». 


\section{EL FALLO SERÁ INAPELABLE}

Una cláusula de estilo que suelen insertar la mayoría de las convocatorias de premios literarios es la que afirma que el fallo del jurado será inapelable. En algún caso, la redacción es todavía más contundente:

«La participación en esta convocatoria implica la aceptación de su contenido y del fallo del jurado, que será inapelable. Cualquier anomalía o duda que pueda surgir en el proceso de selección, deliberación y concesión del premio podrá ser estudiada, interpretada y solucionada por el Jurado, que se reserva el derecho de tomar iniciativas no reflejadas en la convocatoria siempre que contribuyan al mejor desarrollo de la misma» ${ }^{41}$.

En otros casos, no solo se excluye impugnar la decisión final del jurado, sino también las previas: «Las decisiones de admisión tomadas por el Departamento de Cultura y el dictamen del Jurado son inapelables» ${ }^{42}$.

Por mucho que se repita ese estribillo, en un Estado de Derecho nada de lo que hacen las Administraciones Públicas es inapelable. La concesión de un premio literario, como todo acto de la Administración, puede y debe controlarse de acuerdo con los principios sentados por la Constitución en sus arts. 103 («sometimiento pleno de la Administración Pública a la Ley y al Derecho») y 106 («los Tribunales controlan la potestad reglamentaria y la legalidad de la actuación administrativa»). El Tribunal Constitucional ha afirmado que «de estos preceptos se deduce la existencia de un control general o universal de la legalidad de la actuación administrativa, sin excepciones ni reductos inmunes a dicho control» ${ }^{43}$.

Alguna convocatoria trata de hacer equilibrios entre la evidencia de que la actuación de la Administración es siempre impugnable, y la tradicional inapelabilidad del fallo del jurado:

«El fallo será inapelable y podrá declararse desierto si, a juicio del jurado, ninguno de los trabajos tuviera la suficiente calidad literaria y originalidad, o no cumpliera con alguno de los requisitos aquí expuestos. (...) El acuerdo de concesión será recurrible en los términos previstos en la ley 39/2015 de 1 de octubre, del Procedimiento Administrativo Común de las Administraciones Públicas, artículos 112 y siguientes» ${ }^{44}$.

¿En qué quedamos? ¿Se puede o no se puede impugnar la decisión de concesión del premio? Para aclarar un poco la cuestión hay que acudir a la llamada doctrina de la discrecionalidad técnica, que se ha elaborado por la jurisprudencia sobre todo en relación a los tribunales calificadores de procesos de selección de personal. Se ha entendido que la misión del tribunal que juzga una oposición u otro procedimiento competitivo es ofrecer al órgano resolutorio los conocimientos técnicos necesarios para poder tomar la decisión adecuada. En el caso que nos ocupa, los conocimientos de técnica literaria para poder elegir la obra que mayores méritos en ese campo posea. La doctrina de la discrecionalidad técnica establece una presunción iuris tantum de acierto y razonabilidad de la actuación de esos órganos técnicos basada en su especialización e imparcialidad. En un principio se afirmó que no cabe sustituir el juicio técnico del tribunal calificador por el de otras personas u órganos administrativos o judiciales que carecen de esos conocimientos, por lo cual no cabía cuestionarlo mediante un recurso. La cláusula del fallo inapelable sigue anclada en esa idea. Pero, con el tiempo, la jurisprudencia ha ido afinando el concepto para evitar crear zonas de actuación administrativa excluidas de control ${ }^{45}$. Se ha ido afirmando, primero, que aunque los jueces no pudieran entrar en el juicio técnico sí podían comprobar el cumplimiento de los elementos reglados (competencia del órgano, plazos, procedimiento, modo de adoptar el fallo, etc.), o lo que se ha denominado «aledaños» del núcleo de la decisión técnica. Pero, posteriormente, los jueces han ido entrando también a comprobar que en las decisiones de los órganos de selección no se produzca desviación de poder (utilizar sus facultades para perseguir objetivos distintos de los que las justifican), arbitrariedad, ausencia de motivación del juicio técnico, error manifiesto, casos todos ellos en los cuales, si se ofrece prueba suficiente (incluida prueba pericial),

41 Cláusula decimocuarta de la convocatoria del 24 Premio de Novela Ciudad de Badajoz (18.000 euros), aprobada por el Ayuntamiento de Badajoz (Boletín Oficial de la Provincia de Badajoz núm. 155, 4 de agosto de 2020).

42 Base 6 de la ya citada convocatoria del XXVIII Concurso de Prosa del Ayuntamiento de Los Molinos.

43 Sentencia núm. 21/1986, de 14 de febrero.

44 Base octava de la convocatoria del XXIV Certamen Literario Internacional Ciudad de Getafe 2020 (10.000 euros), aprobada por el Ayuntamiento de Getafe (Madrid) y publicada en su página web.

45 Sentencia del Tribunal Supremo de 18 de julio de 2012: «Sobre los límites de la discrecionalidad técnica hay ya una consolidada jurisprudencia de este Tribunal Supremo y del Tribunal Constitucional, caracterizada por el permanente esfuerzo de ampliar al máximo y perfeccionar el control jurisdiccional previsto constitucionalmente frente a toda actuación administrativa (artículo 106.1 CE)». 
puede quedar desvirtuada la presunción de acierto de la decisión y esta puede ser anulada por los órganos judiciales. Actualmente, hay muchos autores (Fernández, 2015, Gil Franco, 2016) que vienen a considerar que ha perdido su sentido original la doctrina de la mal llamada discrecionalidad técnica; en realidad, como dice Fernández (2015, p. 216), no se trata de discrecionalidad sino de simple valoración técnica, los tribunales de selección no pueden actuar discrecionalmente, adoptando la decisión que más les guste entre las posibles, sino valorando cuál es la más adecuada con arreglo a las normas de la convocatoria, y esa valoración puede ser revisada. Lo mismo es aplicable al fallo del jurado de un premio literario ${ }^{46}$. El criterio sobre técnica literaria no puede ser usurpado por un juez de lo contencioso-administrativo ante el que se recurra la concesión del premio, pero podrá examinar si el fallo se ajusta a derecho, en particular, si se ajusta a las bases reguladoras y a la convocatoria, y de que hay prueba suficiente de su acierto y racionalidad. Si en un concurso de poesía se premia una novela, es obvio que el juez anulará el fallo. Si en la reunión del jurado participan y votan miembros no designados por el órgano competente, igualmente dictará la anulación. Si se premia una obra presentada fuera de plazo, o si los miembros del jurado no se han leído ni una de las obras presentadas al premio, también. Es decir, hay muchos motivos por los cuales la actuación del jurado es perfectamente apelable. La afirmación contraria que se contiene en las convocatorias es contraria a la ley.

Pese a que toda actividad de las entidades locales es impugnable ante la jurisdicción contenciosoadministrativa, apenas hay jurisprudencia que podamos citar respecto de la concesión de premios literarios (sí sobre su tributación). No es extraño. Los escritores no suelen recurrir, ni las convocatorias ni el acto de concesión, pese a que acumulen sobradas causas de invalidez. De un lado, por desconocimiento; de otro, porque tienen cosas mejores que hacer. En este país sigue siendo válida la maldición de «tengas pleitos y los ganes». El funcionamiento de la Justicia deja mucho que desear y pocas veces sale a cuenta, incluso llevando razón, gastar tiempo, dinero y desvelos en presentar recursos frente a un enemigo tan difícil de vencer como la Administración, que nunca tiene prisa y siempre dispara con pólvora del rey. La dificultad aumenta si hay que pleitear desde otra ciudad u otra provincia lejana, incluso desde otro país; en los premios literarios en lengua castellana muy a menudo hay concursantes de ambos lados del charco. Por otra parte, es normal preferir no enemistarse contra quienes reparten los premios. Uno nunca sabe si se la van a guardar y va a sufrir las consecuencias de ponerse gallito, incluso en un futuro lejano, sabiendo que habrá más convocatorias en años sucesivos.

Añadamos las dificultades prácticas que sufriría cualquier aspirante a un premio literario para poder recurrir nada, dificultades que ayuntamientos y diputaciones se encargan de elevar a la enésima potencia. Con mucha frecuencia, el autor ignora si su obra ha llegado a su destino, si ha sido admitida, si ha sido leída por el jurado, quiénes componen el jurado, por qué han premiado a la obra ganadora y con qué otras obras competía. Los anónimos concursantes no son notificados de nada; se enteran del fallo, si se enteran, por la prensa. Ya hemos señalado que las entidades convocantes, a despecho de lo que digan las leyes, se niegan a mantener correspondencia con ellos, lo dejan clarito en las bases: «Los trabajos presentados no podrán ser retirados y se reciclarán las copias originales. La entidad organizadora no está obligada a mantener ningún tipo de relación con los participantes» ${ }^{47}$. Reciclar es un verbo mucho más bonito que destruir, pero lo

46 Una de las poquísimas sentencias que existen en esta materia, la del Tribunal Supremo de 13 de junio de 1986, acogía la doctrina de la discrecionalidad técnica: «El control jurisdiccional a que el artículo 106.1 de la Constitución, sujeta en su conjunto a la actividad administrativa sólo alcanza, en materia de adjudicación de premios por un Jurado calificador, al mantenimiento de la imparcialidad del mismo a través del derecho de recusación de sus componentes por el participante -artículo 20 de la Ley de Procedimiento Administrativo- y de las bases o condiciones preestablecidas que son garantías de objetividad, legalidad y acierto para aquella participación, las cuales, sólo en el caso de incompletas, ineficaces o contrarias a la igualdad constitucional serían asequibles a la revisión contencioso-administrativa cuando el premio y el concurso para adjudicarlo emanan de ente u organismo público y se financia con fondos públicos la actividad administrativa de índole premial; sin embargo, en el caso de que la valoración del fondo o juicio selectivo del mérito en sí de la obra o actividad del participante, y de su adecuación al interés público promotor que es causa jurídica de dicha actividad premial, se remite a la decisión de un jurado o tribunal específicamente para cada convocatoria de premio, la actividad administrativa de referencia participa de la estructura contractual de común sumisión del ente convocante y de quien acude a la convocatoria al juicio técnico de aquel jurado, el cual, no cabe así calificar en su fondo o contenido decisorio de actividad administrativa sujeta al control jurisdiccional, toda vez que por propia naturaleza resulta inasequible al mismo sustituir por un juicio de legalidad lo que es de suyo juicio técnico al que en modo arbitral, ambas partes, Administración y participante, se han sometido previamente y con exclusiva referencia a concretos componentes del jurado calificador, también de imposible sustitución, por el incumplimiento que implicaría de la voluntad concordante de las partes, por la prueba pericial que necesariamente habría de instrumentar el juicio de legalidad característico de la revisión contencioso-administrativa». La sentencia entra a valorar, no obstante, un acuerdo del jurado en cuanto a exclusión de una de las obras presentadas por incumplir las bases de la convocatoria.

${ }_{47}$ Base 9 de la convocatoria del XXXIV Premio Internacional de Poesía Antonio Oliver Belmás 2020 (7.200 euros), aprobada por el Ayuntamiento de Cartagena (Murcia) y publicada en su página web. 
que nos están diciendo es que, una vez otorgado el premio, el Ayuntamiento procede, en lenguaje de novela policíaca, a destruir cualquier rastro del delito. Otras convocatorias no se andan por las ramas: «Los ejemplares no premiados no se devolverán; se destruirán a partir de los treinta días del fallo. No se mantendrá correspondencia con los autores no premiados»" 4 ; "Las obras no premiadas así como sus correspondientes plicas, no serán devueltas, siendo destruidas después del fallo del jurado sin que quepa reclamación alguna» ${ }^{49}$. En el supuesto caso de que un intrépido concursante, una vez otorgado el premio, se dirija a la entidad convocante pidiendo información, le darán con la convocatoria en las narices. Si, aun así, persiste y lleva el asunto a los tribunales, resultará que, salvo la obra premiada y su plica, se han destruido todas las demás obras con sus plicas. No hay manera de saber quién concursó y con qué obras. Las evidencias se han volatilizado. La tarea probatoria por parte del recurrente sería ciclópea.

Por supuesto, esa previsión de destrucción de documentación que confiesan sin reparo las convocatorias de premios literarios municipales y provinciales es manifiestamente ilegal y, como otras cláusulas de las convocatorias, inválida. Las Administraciones Públicas tienen obligación de conservar en sus archivos toda la documentación que forma parte de un expediente administrativo a disposición de los interesados y de los órganos judiciales si la reclamaran por haberse interpuesto un recurso ${ }^{50}$. Además, esos archivos forman parte del patrimonio documental protegido por la ley ${ }^{51}$. No se pueden destruir los documentos alegremente, sino a través de un procedimiento reglado que acredite su falta de valor ${ }^{52}$. Pero parece ser que quienes aprueban esas convocatorias no tienen conciencia de que están tramitando un procedimiento administrativo y de que todos los documentos aportados por los interesados forman parte del expediente y deben ser conservados.

\section{EL OSCURO PAPEL DE LAS EDITORIALES}

Hay convocatorias de premios literarios en las que la entidad local se desentiende de la posterior publicación de la obra inédita premiada, pero son las menos. Normalmente, forma parte del premio que la obra sea publicada; en unos casos, por la propia Administración convocante; en otros casos, por alguna editorial a la que posteriormente cederá los derechos correspondientes; y muy frecuentemente, por una editorial que aparece ya mencionada en la propia convocatoria del premio como colaboradora en su gestión. Comparando las convocatorias de premios otorgados por entidades locales y los que conceden las editoriales en solitario, da la impresión de que, a menudo, las entidades locales se han limitado a hacer suya una redacción elaborada por un editorial, sin molestarse en adaptarla a las exigencias jurídicas propias de una Administración Pública.

Qué papel juegan esas editoriales en el procedimiento de concesión de premios resulta una cuestión no siempre clara. En algunas ocasiones existe un convenio de colaboración entre el ayuntamiento o la diputación y la editorial, es usual que la entidad local asuma el gasto que supone abonar la dotación económica del premio y el procedimiento de concesión, mientras que la editorial se compromete a la edición de la obra

48 Base 12 de la convocatoria del Premio de Novela Histórica Medieval Ciudad de Calatayud (5.000 euros), aprobada por el Ayuntamiento de Calatayud (Zaragoza) y publicada en su página web.

49 Base sexta de la citada convocatoria del I Premio Ciudad de Estepona de Novela.

50 Art. 17.2 de la LPAC: «Los documentos electrónicos deberán conservarse en un formato que permita garantizar la autenticidad, integridad y conservación del documento, así como su consulta con independencia del tiempo transcurrido desde su emisión. Se asegurará en todo caso la posibilidad de trasladar los datos a otros formatos y soportes que garanticen el acceso desde diferentes aplicaciones. La eliminación de dichos documentos deberá ser autorizada de acuerdo a lo dispuesto en la normativa aplicable».

51 Art. 49.2 de la Ley 16/1985, de 25 de junio, del Patrimonio Histórico Español: «Forman parte del Patrimonio Documental los documentos de cualquier época generados, conservados o reunidos en el ejercicio de su función por cualquier organismo o entidad de carácter público, por las personas jurídicas en cuyo capital participe mayoritariamente el Estado u otras entidades públicas y por las personas privadas, físicas o jurídicas, gestoras de servicios públicos en lo relacionado con la gestión de dichos servicios». Art. 52.1: «Todos los poseedores de bienes del Patrimonio Documental y Bibliográfico están obligados a conservarlos, protegerlos, destinarlos a un uso que no impida su conservación y mantenerlos en lugares adecuados».

52 Art. 55 de la Ley 16/1985, de 25 de junio, del Patrimonio Histórico Español: «1. La exclusión o eliminación de bienes del Patrimonio Documental y Bibliográfico contemplados en el artículo 49.2 y de los demás de titularidad pública deberá ser autorizada por la Administración competente. 2. En ningún caso se podrán destruir tales documentos en tanto subsista su valor probatorio de derechos y obligaciones de las personas o los entes públicos. 3. En los demás casos la exclusión o eliminación deberá ser autorizada por la Administración competente a propuesta de sus propietarios o poseedores, mediante el procedimiento que se establecerá por vía reglamentaria». El Real Decreto 1164/2002, de 8 de noviembre, regula la conservación del patrimonio documental con valor histórico y el control de la eliminación de documentos de la Administración del Estado; otras normas autonómicas similares son de aplicación a las entidades locales. 
ganadora y a participar en el nombramiento de miembros del jurado. En otras ocasiones, no se sabe si hay convenio escrito, al menos no se hace público. Existe otro tipo de convenios, donde una editorial aparece como beneficiaria de la subvención por la organización de un premio y la edición de la obra premiada, distinto del que aquí nos ocupa, pues quien convoca y concede el premio no es la entidad local. En todo caso, la existencia de una editorial que va a participar en el procedimiento como entidad colaboradora de una Administración exige, conforme a la LGS, formalizar un convenio ${ }^{53}$. Además, la selección de la editorial no puede hacerse libremente, sino que debe aplicarse lo que dispone el art. 16.5 de la LGS:

"Cuando las entidades colaboradoras sean personas sujetas a derecho privado, se seleccionarán previamente mediante un procedimiento sometido a los principios de publicidad, concurrencia, igualdad y no discriminación y la colaboración se formalizará mediante convenio, salvo que por objeto de la colaboración resulte de aplicación plena el Texto Refundido de la Ley de Contratos de las Administraciones Públicas, aprobado por el Real Decreto Legislativo $2 / 2000$, de 16 de junio» ${ }^{54}$.

No parece que se esté observando este precepto en la conclusión de los convenios o contratos de colaboración, en los diarios oficiales y en los portales de contratación no se encuentra rastro de procedimientos públicos de concurrencia. En todo caso, haya o no ese procedimiento y un convenio escrito, las editoriales, cuando menos, han de considerarse como «terceros relacionados con el objeto de la subvención» obligados a prestar colaboración con los órganos que ejerzan las funciones de control a que se refiere el art. 46 de la LGS (Giraldes, 2015).

Otra cuestión problemática sobre el papel de las editoriales es su facultad de nombrar miembros del jurado. Si se trata de una persona vinculada a la editorial, un directivo o un empleado, es obvio que se puede producir un conflicto de intereses y un motivo legal de abstención ${ }^{55}$. La editorial tiene un interés obvio en el asunto; va a recibir la cesión de los derechos de autor de la obra premiada y adquiere la obligación de realizar su publicación asumiendo el riesgo empresarial. Su interés, legítimo pero distinto del de la Administración, es que el premio recaiga en una obra lo más comercial posible, y en un autor conocido, para poder vender el mayor número de ejemplares. El objetivo de la Administración es satisfacer algún interés público que debiera quedar definido en las bases reguladoras y en la convocatoria del premio: impulsar la creación literaria, contribuir al dinamismo del sector cultural, fomentar el conocimiento de determinados temas, promocionar autores noveles, favorecer la profesionalización de los escritores, rendir homenaje a determinado literato, etc. Es obvio el riesgo de desnaturalizar los fines del premio si la editorial tiene una participación decisiva y directa en el jurado. La finalidad perseguida por la Administración no puede ser que una empresa privada gane dinero. Distinto es el caso de que la editorial se limite a proponer a personas de reconocida cualificación técnica sin dependencia o intereses comunes con la empresa.

También resulta bastante vidriosa la relación que se establece entre el autor premiado y la editorial que ha de publicar su obra. Con frecuencia, en la convocatoria no se dispone nada al respecto, serán el autor y la editorial los que tengan que negociar el contrato de edición, lo cual ofrece escasas garantías para ambos. Pero, en otros casos, sucede lo contrario, que la convocatoria del premio impone al autor unas condiciones leoninas, valgan de ejemplo las siguientes que cualquier agente literario o abogado aconsejaría no firmar a ningún escritor ${ }^{56}$ :

«En el preceptivo contrato de edición, que el autor deberá suscribir a la percepción del Premio, éste cederá en exclusiva y para todo el mundo los derechos de explotación de la obra ganadora, incluidos los de traducción y audiovisuales, así como la gestión de acuerdos con terceros para su más amplia explotación. Los editores podrán efectuar, durante el período máximo que permita la Ley, cuantas ediciones juzguen oportunas de la obra, decidiendo según su cri-

53 Art. 16.1. de la LGS: «Se formalizará un convenio de colaboración entre el órgano administrativo concedente y la entidad colaboradora en el que se regularán las condiciones y obligaciones asumidas por ésta».

54 Hoy esta remisión hay que entenderla hecha a la Ley 9/2017, de 8 de noviembre, de Contratos del Sector Público.

55 Art. 23.2 de la Ley 40/2015, de 1 de octubre, de Régimen Jurídico del Sector Público: «Son motivos de abstención los siguientes: a) Tener interés personal en el asunto de que se trate o en otro en cuya resolución pudiera influir la de aquél; ser administrador de sociedad o entidad interesada, o tener cuestión litigiosa pendiente con algún interesado. (...) e) Tener relación de servicio con persona natural o jurídica interesada directamente en el asunto, o haberle prestado en los dos últimos años servicios profesionales de cualquier tipo y en cualquier circunstancia o lugar».

56 Base 8 de la convocatoria del XIII Premio Logroño de Narrativa (20.000 euros), aprobada por el Ayuntamiento de Logroño, publicada en la página web municipal y en las de sus entidades colaboradoras Fundación Caja Rioja y Algaida Editores. 
terio el número de ejemplares, precios, distribución, modalidad y formato de la edición, etc., de las que el autor percibirá el $10 \%$ del PVP (impuestos excluidos) de los ejemplares vendidos en edición de tapa dura y el $5 \%$ del PVP (impuestos excluidos) en edición de bolsillo y el $25 \%$ del PVP (impuestos excluidos) en edición digital, no devengándose cantidad alguna hasta cubrir el anticipo, del que tampoco podrá reclamarse al autor devolución alguna».

Es usual esa cláusula por la cual el galardonado no percibe derechos de autor por la primera edición, los cuales se entienden satisfechos con la cuantía del premio, considerado como un anticipo. Quiere decir eso que es la editorial quien ingresará el importe de tales derechos de autor, es decir, que de hecho recibe también una subvención por la cantidad equivalente. Su papel, más que de entidad colaboradora, es de entidad beneficiaria de la actividad subvencionadora y, a menudo, como ya se ha dicho, sin pasar por ningún procedimiento público de selección.

\section{ABANDONAD TODA ESPERANZA}

Lasciate ogni speranza, voi ch'entrate, advirtió Dante a quienes traspasaran las puertas del infierno. Algo parecido cabe decir a los escritores que presentan su obra a ciertos premios literarios. Con ese acto, en la práctica renuncian a casi todos los derechos que las leyes conceden a los ciudadanos en sus relaciones con las Administraciones Públicas. Como por ensalmo, retroceden a aquellos tiempos, parece que nunca superados del todo, en los que solo había súbditos obedientes sin derecho a queja y que debían agradecer las mercedes que, graciosamente, pudieran recibir de sus señores.

¿Se amañan también los premios literarios municipales y provinciales? Imposible saberlo. Solemos tener tan poca información sobre lo que sucede en sus entretelas como del interior de un agujero negro.

Quizás se abriera un pequeño resquicio a la esperanza si, en desarrollo de la LGS, el Gobierno aprobara el demorado reglamento para premios educativos, culturales y científicos, y si quienes los conceden tomaran conciencia de la necesidad de aplicarlo.

\section{REFERENCIAS BIBLIOGRÁFICAS}

Bértolo, C. (25 de febrero de 2017). Cloacas y premios literarios. CTXT, Contexto y Acción. Consultado el 1 de noviembre de 2020. https://ctxt.es/es/20170222/Culturas/11313/el-ministerio-premios-literarios-corrupcion-premioplaneta-literatura.htm

Fernández, T.-R. (2015). La discrecionalidad técnica: un viejo fantasma que se desvanece, Revista de Administración Pública, 196, 211-227. http://www.cepc.gob.es/publicaciones/revistas/revistaselectronicas?IDR=1\&IDN=1339\&I $\mathrm{DA}=37306$

Gil Franco, A. J. (2016). A propósito de la STS de 16 de diciembre de 2014, análisis jurisprudencial de la discrecionalidad técnica: ¿acaso estamos ante una nueva fase en la evolución del control jurisdiccional de la discrecionalidad técnica?, Anuario de la Facultad de Derecho (Universidad de Alcalá), 8, 189-224. https://ebuah. uah.es/dspace/handle/10017/24206

Giraldes Gutiérrez, L. S. (2015). Estudio sistemático de la posición jurídica del beneficiario en la relación subvencional. Análisis de las posibilidades de reforma y mejora, Revista española de derecho administrativo, 174, 435-460.

Izu Belloso, M. J. (2009). El régimen jurídico de los premios concedidos por las Administraciones Públicas, Revista Jurídica de Navarra, 47, 125-180. http://www.navarra.es/appsext/DescargarFichero/default.aspx?codigoAcceso=P dfRevistaJuridica\&fichero=RJ_47_I_4.pdf

Marín Yarza, M. (13 de febrero de 2017). ¿A quién sirven los premios literarios? El País [suplemento literario Babelia]. Consultado el 1 de noviembre de 2020. https://elpais.com/cultura/2017/02/10/babelia/1486723630_593071.html 